\title{
An Experimental Analysis of Individual Irregularities Under the Temptation of Money: Network Simulation Interactive Platform Based on HTML5
}

\author{
Pan Cui ${ }^{1}$, Xuanwen Liu ${ }^{1} \&$ Fenfang Lin ${ }^{1}$ \\ ${ }^{1}$ Institutes of Psychological Sciences, Hangzhou Normal University, Zhejiang, China \\ Correspondence: Xuanwen Liu, Institutes of Psychological Sciences, Hangzhou Normal University, Zhejiang, \\ China.
}

Received: November 20, 2019

Accepted: December 10, 2019 Online Published: December 14, 2019

doi:10.20849/abr.v4i3.689

URL: https://doi.org/10.20849/abr.v4i3.689

\begin{abstract}
Irregularities in economic activities are actually the result of mutual game between different stakeholders. This research combines psychology and experimental economics to analyze irregularities. This research is done on the HBuilder software platform, using HTML5 and other technologies. According to the Nash Equilibrium Theory, the behavioral trajectory of the participant is described. In the real incentive situation, the individual's decision-making behavior in the face of social dilemma is investigated. From the perspective of cost-benefit, the game characteristics of individual irregularities are analyzed. The exogenous punishment mechanism and the inherent personality trait are respectively Dimensions are explored. Experiment result shows: The exogenous punishment mechanism will have a significant inhibitory effect on individual irregularities. The level of risk appetite is related to gender and determines the individual's risk-taking tendency.
\end{abstract}

Keywords: nash equilibrium, punishment, irregularities, incomplete information game, experiments with economic principles, experimental psychology

\section{Foreword}

Economic activities are an important part of our society. Pursuing economic benefits and striving for maximum benefits are inevitably the choice of most people. From an economic point of view, people's social behavior aims to maximize the resources or benefits they need at a minimum cost (Ma, C., 2005). From a sociological perspective, it is found that individual behavior is not always a single self-interested behavior, individuals also exhibit prosocial altruistic behavior (Wang, J., 2009). In a society with rapid economic development, individuals will face a variety of temptations of interest, and irrational factors will gradually emerge. How will individuals who possess information superiority and power advantage make decisions?

The process of mutual gaming between different stakeholders is extremely prone to irregularities. The analysis of individual violations in economic activities is the main focus of many researchers. As the main participating groups in business activities, senior managers who play a pivotal non-replacement role that make decisions for the enterprise. Therefore, the research in this article is of great practical significance. Most studies on violations in the field of economics are empirical: market data is used as a research sample, and post-hoc analysis principles are used to track and analyze the related factors. From the analysis of macro factors, many theoretical and practical foundations have been laid in this field. But at the same time, due to the influence of its data availability which come from the database. Such as, and there may be errors in itself, some of the information classification is not clear enough, or others involving manual judgment and collation may reduce the accuracy of the data and the reliability of the analysis results Degree will be affected (Rajan, G. \& Wulf, J., 2006; Aoki, M., 2011; Xu, WJ, 2017; Liu, FZ, 2017). This article starts from theories of modern enterprise theory, The Principal-agent theory, Cost-Benefit Theory, etc., draws on some existing experimental research ideas based on experimental economics, and analyzes individual behaviors based on existing literature data combing and behavior principles. The behavioral trajectory of the participant is portrayed: for people, in order to ultimately maximizing personal interests, the decision-making behavior in the actual ecological environment shows concession, and it is core to develop economic relations based on change and game principles. We select the HBuilder software platform, use HTML5 and other technologies to develop a networked experimental 
environment. The purpose is to reduce the interference of the participant's uncontrollable factors on the experimental results in previous experiments by fixing the behavior of one of the participant. Focus more on the behavior change of decision-making subjects and internal and external influence factors, and present the occurrence of irregularities in a more direct way.

\section{Literature Review}

\subsection{The Modern Enterprise Theory}

The core viewpoint of modern enterprise theory: An enterprise is an organic combination of a series of contracts, a way of trading property rights between people, rather than a simple aggregation of physical assets. Jensen interpret the enterprise as a legal entity composed of a complex set of explicit and implicit contracts between different individuals, and clearly states: The contractual relationship is the essence of the enterprise(Jensen, M.C. \& Meckling, W., 1976). Freeman and Blair define the most representative stakeholders as "stakeholders are those who can influence the achievement of an organization's goals or can be influenced by the organization's achievement of the target process" (Freeman, R.E., 1984; Blair, M.M., 1995). Stakeholders include individuals or groups such as shareholders, employees, customers, suppliers, retailers, communities, governments, and so on. According to Honghui Chen's empirical research, each type of stakeholder has multiple interests for the enterprise, the interests of different stakeholders are different, and the interests of each stakeholder are not single but with rich content (Chen, H.H., 2004). Since various stakeholders demand the enterprise from the perspective of their own interests and needs, the interests pursued by different stakeholders are not only different, but also likely to have conflicts. Therefore, the mutual game between different stakeholders is extremely easy to create irregularities.

\subsection{The Principal-Agent Theory}

The Principal-agent theory was first proposed in the 1930s. American economists Berle and Means believed that the ownership of the company should be separated from the management rights (Berle, A. \& Means, G., 1932). The owner is the principal and the majority shareholder of the company. They hand over the management rights to the agent and the agent to manage the company. Jensen and Meckling stated in the research literature that the principal-agent relationship is a contractual relationship: the agent acts on behalf of the principal, and the agent has certain decision-making power (Jensen, M.C. \& Meckling, W., 1976). In the early 1970s, Ross proposed that principal-agent is the agent's right to exercise in the agreement under the premise of the exercise of the principal's rights (Ross, S., 1973). The agency relationship is generated because the agent makes the decision related to the principal's interests for the client.

Pratt and Zeckhauser argue that the principal-agent relationship exists in any organization or cooperation involving two or more people (Pratt, J. \& Zeckhauser, R., 1985). As long as one person's decision depends on another person, the principal-agent relationship is created (Peters, M., 2003). The party making the decision is the agent, and the party to be relied on is the principal. Obviously, both parties acting as rational economic, because the principal pursues the maximization of income, the agent wants to maximize the salary level and skill, resulting in different effect functions and different pursuit directions (Liu, Y.G. \& Jiang, N.Y., 2006). There is a certain conflict in the choice of interests. Therefore, it is inevitable that the agent deviates from or even sacrifices the interests of the principal to seek private benefits. It can be seen that the principal-agent problem is very common.

What is used here is to establish the relationship between the citizen and a certain department executive as the relationship between the principal and the agent. Citizens defend their interests by transferring money privately to officials, and officials receive remuneration through such agency.

\subsection{The Cost-Benefit Theory}

Cost is the value of the resource that pays for a certain purpose, and the benefit refers to the benefit gained by the input of the former (Liu, B.R., 2003). Expecting income above cost is the primary starting point of a rational economic man and the basic rational principle of human society. Simply put, the difference between the benefit and the cost is as large as possible to maximize the benefits.

The cost of irregularities refers to the price paid by the actors for specific irregularities. It is divided into two parts: one is the resource consumption, that is, the time, mental power, physical strength and other resources that the main body has paid in the event of irregularities; the second is the opportunity cost, that is, the subject gains income when the irregularities occurs, at the same time, another benefit that was abandoned. The cost of irregularities is expressed by the formula: cost $=$ inevitable cost + prescribed cost $x$ penalty rate. The inevitable cost refers to the resource loss and opportunity cost that the subject has to bear when selecting the irregularities. 
The prescribed cost refers to the price paid by the law when the subject violates the rules. It is the sanction imposed by the regulations on the irregularities. For the main body, the prescribed cost is a possible cost, and the cost can be avoided when the irregularities is not disclosed. The penalty rate is the probability of being punished when irregularities occurs. The subject risked the cost of the irregularities in order to gain interest. The proceeds of irregularities are the income that the entity receives in the event of a specific risk of non-compliance. It is divided into two parts: one is resource possession; the second is the timing, that is, the subject obtains an opportunity to engage in an activity through the occurrence of irregularities.

This paper analyzes the irregularities of the subject, considers the impact of the prescribed cost and the penalty rate on the subject's behavior, and explores the relationship between the inevitable resource cost and the subject decision.

\subsection{Nash Equilibrium}

Game theory was first proposed by von Neumann $(1903 \sim 1957)$. He emphasized that the two people use multiple strategies to change their own confrontation strategies in an equal game to achieve the goal of winning. Games are usually divided into cooperative games and non-cooperative games. Non-cooperative game refers to how to maximize the respective interests under the given constraints, and finally achieve the balance of power. The key is that when participants choose their own actions, the priority is how to protect their own interests. The cooperative game emphasizes Collectivism and Collective Rationality, which is efficiency and fairness. It is the study of how to distribute the cooperation when people reach cooperation, that is, the problem of income distribution. The non-cooperative game is to study how people choose their decisions in the situation where interests affect each other to maximize their own benefits, that is, the choice of strategy. Nash equilibrium is the result of the rational choice of the players in the game, and it is the knot of the game between the individual and the environment.

The basic criteria for the establishment of the game model in this paper: "Build your own strategy based on the assumption that the opponent will act in its best interests". In this state, each participant makes decisions based on the price set by others.

\section{Method}

This paper mainly draws on the design idea of Abbink's game experiment paradigm, and studies the game behavior of both sides in the context of incomplete information (Abbink et al., 2002, 2004, 2006; Zhang, H.H., 2016). The purpose is to explore the impact of internal and external dimensions on irregularities, and present the process of irregularities in a more direct way. This lab builds a virtual social context that includes two main social roles: company bosses and executives in a department. The basic design idea of the experiment is: First, the company boss will consider privately contacting a department executive to seek benefits in order to maximize personal income. Secondly, a department executive needs to respond according to the behavior of the company's boss, whether it will decisively refuse or accept money and accept money to provide convenience services to enterprises.

Considering that the behavior of the two subjects under the interaction situation will be affected by many factors, this effect will impose certain limitations on the experimental observation, and at the same time it is easy to confuse the experimental results. In order to more clearly and deeply explore the individual's decision-making behavior on social dilemmas under the real incentive situation. The experiment will fix the principal's behavior (ie, the boss of the enterprise), and describe the decision of the client according to the Nash equilibrium principle and a large number of empirical research results. The rules are as follows: The first round of the game starting value is randomly selected by the system within the range of $0-25$ tokens; The second round $t$ value is determined by the decision of the first round of the test. If the type of the decision is $\mathrm{R}$ or $\mathrm{n}$, the value of the transfer amount increases. At this time, when $0 \leq \mathrm{t}<50$ tokens, $\Delta \mathrm{t}=4,5,6$ random tokens, when $50 \leq \mathrm{t}<100$ tokens, $\Delta \mathrm{t}=9,10,11$ random tokens, when $100 \leq \mathrm{t} \leq 200$ tokens, $\Delta \mathrm{t}=19,20,21$ random tokens; If the trial decision type is $\mathrm{y}$, the transfer amount $\mathrm{t}$ value decreases or remains unchanged. At this time, when $0 \leq \mathrm{t} \leq 25$ tokens, $\Delta \mathrm{t}=0$ tokens, when $25<\mathrm{t} \leq 50$ tokens, $\Delta \mathrm{t}=-5$ Token, when $50<\mathrm{t} \leq 100$ tokens, $\Delta \mathrm{t}=-10$ tokens, when $100<\mathrm{t} \leq 200$ tokens, $\Delta \mathrm{t}=-20$ tokens).if the first round random value is 0 token, then The starting value of the second round of the game is randomly selected by the system within the range of $0-25$ tokens, and the change rule is consistent with the above; and so on for a total of 20 rounds.

According to the experimental design ideas, it can be summarized as follows: On the one hand, the business owner has two behavioral decisions: do nothing or contact departmental executives. On the other hand, departmental executives have three behavioral decisions: rejection, accepting money but not giving service, accepting money and giving convenient services. In order to reflect the experimental design ideas more 
intuitively and visually, the role objects in this experiment will be replaced by letters: B stands for the business owner, $\mathrm{P}$ stands for departmental executives, $\mathrm{t}$ stands for the amount, and A stands for acceptance (Figure 1). The entire experimental process was set to a fixed group matching experiment, that is, the subjects and their assigned roles were not replaced in 20 rounds of experiments.

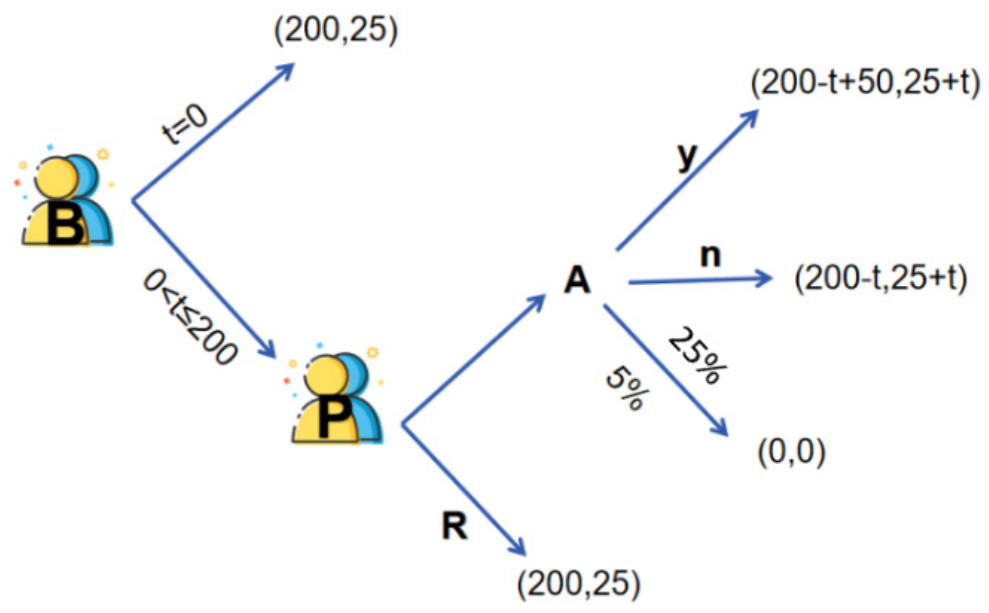

Figure 1. Experimental model diagram

\subsection{Schematic Diagram of the Game Model}

\subsubsection{Basic Rules of the Game Model}

(1) Suppose there are two participants: one is the business owner, the other is the department executive.

(2) There are three strategic choices for departmental executives: not accepting money, keeping the market up and running, accepting money but keeping the market up and running (irregularities) and accepting money and giving convenience services (irregularities).

In order to facilitate the analysis and establishment of the game model, the following assumptions are made about the relevant parameters: the additional income obtained by the departmental executives in irregularities of regulations is $t(t \geq 0)$, and if the departmental executives do not violate the rules, they will not receive these benefits. It will generate the opportunity $\cos t-t(t \geq 0)$; the business owner may bring $50-t(t \geq 0)$ of income due to the irregularities of the departmental executives, but it may also directly lose $t(t \geq 0)$.

\subsection{Experimental Methods and Processes}

A total of 100 Chinese college students from a university in Hangzhou, China participated in the study for partial course credit ( 62 female; $\mathrm{M}=20.6, \mathrm{SD}=5.36$, range: 18-26), and students in psychology and computer science were not recruited.

In order to meet the assumptions of the rational economic man of the experimental participants, an incentive mechanism was set up for the experiment: experimental reward $=$ basic experiment fee $+5 \%$ task cumulative income. The experiment was an inter-test experiment, and each participant conducted a total of 20 rounds of independent decision-making game experiments. In each round, the participants chose their own decisions based on their own roles and submitted them to the system. Based on the decision-making choices of the participants, the system will calculate the earnings of each participant in the current round, and the current cumulative income will be immediately fed back to the participants. After the round is completed, continue to the next round until the end of the experiment. In each round of experiments, HBuilder software was used to record experimental data in real time: the strategy selected by each participant in the round decision, the length of time spent on the decision, the amount given by the opponent in the round, the result of the round, the proceeds of the round, and Total revenue.

\subsection{Results}

Analysis of the distribution of Strategy choices of subjects in different penalty rate experiments. 


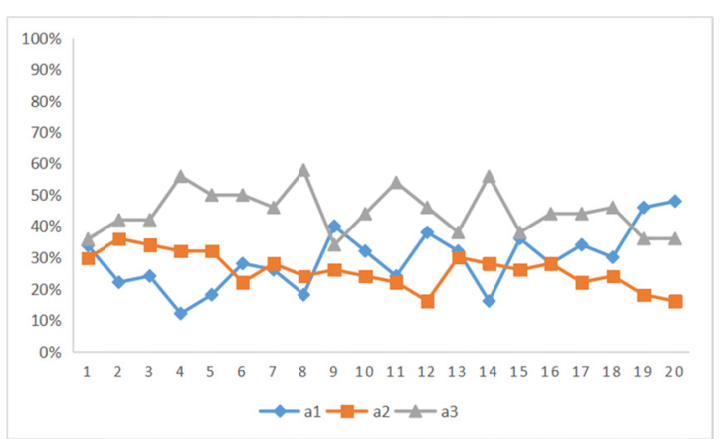

Figure 2. Strategy choices of subjects in low-penalty rate experiments

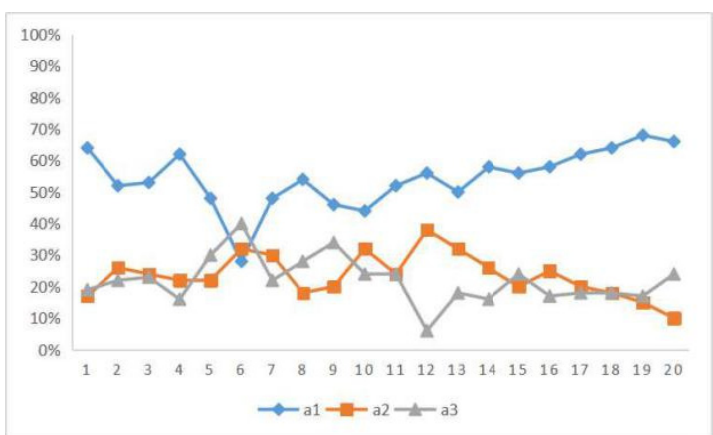

Figure 3. Strategy choices of subjects in high-penalty rate experiments

It can be seen from Figure 2 that in the case of a high-penalty rate of the exogenous punishment mechanism, the number of people who chose the three strategies at the beginning stage is not much different, and the number of people who choose strategy 1 (rejection) accounts for $34 \%$ of the total number. Strategy 2 (accepting money but not giving service) accounted for $30 \%$ of the total number, and people who chose credit 3 (accepting money and giving convenient services) accounted for $36 \%$ of the total.

This is in line with the experimental common sense. At the beginning, everyone is not sure which strategy is the optimal strategy to achieve maximum benefit, and embraces the attitude of waiting and tempting. As the experiment progressed, the experiment participants modified the strategy according to their own income situation and the results of each round. Until the experimental phase of the fourth round, the gap in decision-making distribution was clearly displayed. The number of people who chose Strategy 1 gradually decreased, the number of people who chose Strategy 3 gradually increased, and the number of people who chose Strategy 2 stabilized slightly. It is worth noting that the proportion of people who chose Strategy 1 between the 18 th and 20th rounds increased significantly. According to the subjects description, when the number of rounds is close to 20, they worry about that if their irregularities be found, and due to the external punishment mechanism, the previous cumulative income will be zero. They tend to choose a conservative strategy. Explain that the departmental executives played by the experimental participants have realized that the selection strategy 1 is the one that achieves the least profit, and the selection strategy 3 is the one that achieves the most profit.

It can be seen from Figure 3 that in the case of a high rate of investigation of exogenous punishment mechanisms, the number of people who selected the three strategies at the beginning stage has reached a significant difference, with $64 \%$ of the total number of people choosing strategy 1 (rejection). The number of people who chose the strategy 2 (accepting money but not giving service) was $17 \%$, and the number of people who chose the strategy 3 (accepting money and giving convenient services) accounted for $19 \%$ of the total. As the experiment progressed, the experimental participants modified the strategy according to their own income and the results of each round. The proportion of people who chose Strategy 3 between the third round and the 18th round was significantly stable and slightly fluctuating. It is worth noting that in the fourth round and the 18 th round, the individual decision-making distribution gap is the most obvious, and the number of people choosing Strategy 1 is significantly reduced. In the end, when I was close to 20 rounds, I was also tried to avoid the taboo of the exogenous punishment mechanism and chose a conservative strategy. 


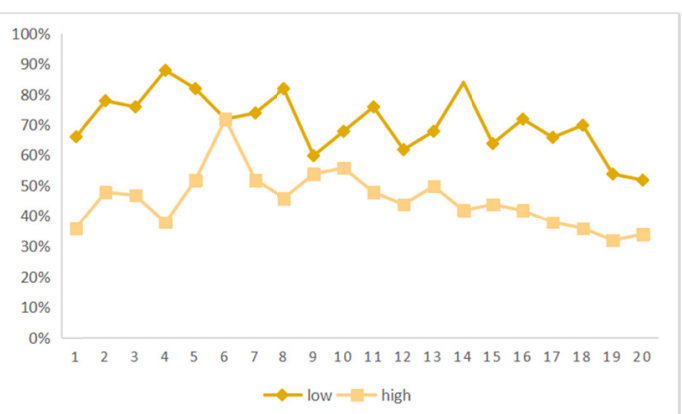

Figure 4. Incidence of irregularities in each round of trials in different penalty rate experiments

Descriptive statistical analysis

Table 1. Demographic variables in different penalty rate experiments

\begin{tabular}{llll}
\hline & low-penalty rate & high-penalty rate & total \\
\hline Gender & $0.48 \pm 0.50$ & $0.41 \pm 0.49$ & $0.44 \pm 0.49$ \\
Age & $21.13 \pm 5.01$ & $20.58 \pm 5.40$ & $20.7 \pm 5.31$ \\
Risk Propensity & $6.58 \pm 10.21$ & $6.52 \pm 10.44$ & $6.56 \pm 10.40$ \\
\hline
\end{tabular}

Note: male $=1$

Table 2. Impact of different penalty rate on the Irregularities Rate and Earnings of Irregularities Independent sample t test

\begin{tabular}{llll}
\hline & low-penalty rate & high-penalty rate & $\mathrm{t}$ \\
\hline Irregularities Rate & $0.71 \pm 0.01$ & $0.46 \pm 0.01$ & $-0.433^{* *}$ \\
Earnings of Irregularities & $17.76 \pm 239.55$ & $9.52 \pm 145.27$ & $-16.12^{* *}$ \\
\hline
\end{tabular}

$* \mathrm{p} \leq .05 . \quad * * \mathrm{p} \leq .01 . \quad * * * \mathrm{p} \leq .001$.

Table 1 reports the demographic characteristics of the participants such as gender and age, as well as the results of the lottery experiment and the main descriptive statistics. Among the different types of experimental groups, female participate in the experiment accounting for $56 \%$ of the total number of participants in the experiment. Participants are slightly more female than male, and the proportion of female and male meet the characteristics of the school distribution. The participants of the experiment are all undergraduate students and master students of this school. There is a slight difference in age, but each group was evenly distributed. According to the results of the lottery experiment, more than half $(50.4 \%)$ of the participants were risk aversers, another $26.8 \%$ were risk neutral, and $22.8 \%$ could be classified as risk appetites. Table 2 shows the result of independent sample $t$ test for analysis after the experimental data is collected. It shows that under high-penalty rate conditions, the individual Irregularities Rate and the Earnings of Irregularities both decreased and reached statistically significant levels.

Combining the distribution of the above two exogenous punishment mechanisms, it can be seen that under the influence of interests, the increase in the amount of the money reduces the ability of individuals to resist temptation and increases the number of irregularities. But in comparison, in a high penalty environment, individual irregularities are constrained and significantly reduced.

\subsection{General Discussion}

After analyzing the experimental results, it can be concluded that: 1 . In the fixed matching, because the interests drive the participants to tend to violate the rules, in the repeated game, the overall behavior characteristics are formed: the initial and the end of the round two The incidence of partial violations is low, and the middle round 
is the high incidence of individual violations. 2. In the case of non-consideration of other factors, the departmental executives in the fixed matching are in pursuit of maximizing profits, and the optimal strategy is to accept money and provide assistance. Through the analysis of the correlation coefficient between the optimal strategy and the income relationship, indicating that when the average income of the strategy rises, the number of people who choose the strategy increases, which is also consistent with the assumption that the pursuit of maximum profit in the experiment. 3. Under the conditions of the ex-existing punishment mechanism with a penalty rate of $25 \%$, the violations of the participants are significantly lower than the $5 \%$-penalty rate condition. It can be seen that by strengthening the supervision and crackdown, the violations can be reduced.

\section{References}

Abbink, K. (2004). Staff Rotation as an Anti-corruption Policy: an Experimental Study. European Journal of Political Economy, 20, 887-906.

Abbink, K., \& Hennig, S. H. (2006). Neutral versus Loaded Instructions in a Bribery Experiment. Experimental Economics, 9(2), 103-121.

Abbink, K., Irlenbusch, B., \& Renner, E. (2002). An Experimental Bribery Game. Journal of Law, Economics and Organization, 18(2), 428-454.

Aoki, M. (2011). Institutions as Cognitive Media between Strategic Interactions and Individual Beliefs. Journal of Economic Behavior \& Organization, 79, 20-34.

Berle, A., \& Means, G. (1932). The modern corporation and Private property. New York: MeMillan.

Blair, M. M. (1995). Corporate ownership. Brookings Review, 16-19.

Chen, H. H. (2003). Theoretical and Empirical Research on Stakeholders of the Firm. Zhejiang University.

Freeman, R. E. (1984). Strategic management a stakeholder approach. Boston Pitman, 276.

Jensen, M. C., \& Meckling, W. (1976). Theory of the firm managerial behavior agency cost and capital structure. Journal of Financial Economics, (3), 305-360.

Liu, B. R. (2003). Theoretical Analysis of cost-benefit of Economy crime. Journal of Guizhou Police Officer Vocational College.

Liu, F. Z. (2017). Manager Fraud,Nature of Ownership and Capital Cost. Xiamen University.

Liu, Y. G., \&Jiang, N. Y. (2006). The Principal-agent theory. Academics in China.

Ma, C. (2005). The Study on the Perceptions of Organizational Politics of the Staffs and Its Effects on Human Resource Management. Jinan University.

Peters, M. (2003). Negotiation and Take it or Leave it in Common Agency. Journal of Economic Theory, 111, 88-109.

Pratt, J., \& Zeckhauser, R. (1985). Principals and Agents: The Structure of Business. Boston: Harvard Business School Press.

Rajan, G., \& Wulf, J. (2006). Are Perks Purely Managerial Excess?. Journal of Political Economy, 79(1), 1-33.

Ross, S. (1973). The Economic Theory of Agency: The Principals Problem. American Economic Review, 63, 134-139.

Wang, J. (2009). Altruism: Economic Model and Data Analysis. Xiamen University.

Xu, W. J., Guan, X. W., Liu, D. H., \& Zhang, W. G. (2017). Evolutionary Game Analysis of Fund Market Endogenous Order Considering the Cognitive Deviation. Systems Engineering, 35(3), 35-41.

Zhang, H. H. (2016). Corrupt Behavior and its Governance: an Experimental Analysis. Zhejiang University.

\section{Copyrights}

Copyright for this article is retained by the author(s), with first publication rights granted to the journal.

This is an open-access article distributed under the terms and conditions of the Creative Commons Attribution license (http://creativecommons.org/licenses/by/4.0/). 